\title{
Effect of Sodium Carboxymethylcellulose and Sorbitol on Anti-Peptic Ulcer Activity of Anredera cordifolia Leaves Extract
}

\author{
Maria Ulfah, Revika Rachmaniar, Egi MR. Sudrajat, Rida W. Fadla, Hary S. Pinuji
}

Department of Pharmacology, Indonesia School of Pharmacy, Bandung, West Java, Indonesia

\begin{abstract}
Anredera cordifolia or binahong is one of the Indonesian medicinal plants that is used to treat peptic ulcer. The purpose of this study was to evaluate the effect of the addition of sodium carboxymethylcellulose (CMC) and sorbitol on anti-peptic ulcer activity of $A$. cordifolia leaves extracts in male Wistar rats. The plants were extracted using decoction method and freeze dried. Three liquid formulas were used i.e., i) a combination of sodium CMC and sorbitol; ii) only sorbitol; iii) extract only. The rats were divided into 6 groups, i.e., positive control (sucralfate $35 \mathrm{mg} / \mathrm{kg}$ body weight); negative control ( $80 \%$ ethanol); normal control; and 3 formulas. After the administration of the liquid formula, all groups, except normal control, were given $80 \%$ ethanol $(15 \mathrm{ml} / \mathrm{kg}$ body weight) to induce peptic ulcer. Antipeptic ulcer activity was evaluated using direct observation on rats gastric mucosa, and histopathology assessment. The result showed that the strongest anti-peptic ulcer was shown by sorbitol only (96.95\% inhibition), followed by the combination of sodium CMC and sorbitol (92.68\% inhibition). The formula which only contained extract showed only $31.70 \%$ inhibition. Statistical analysis showed significant differences between formula 1 and 2 with negative controls. In conclusion, $A$. cordifolia leaves extract with the addition of sorbitol showed the strongest anti-peptic ulcer activity.
\end{abstract}

Keyword: Anredera cordifolia, peptic ulcer, suspense, Wistar rat.

\section{Introduction}

Peptic ulcer is a medical condition characterized by discontinuation of the lining or mucosa of gastrointestinal tract due to excessive gastric acid secretion. Approximately 8.41 per 100,000 Indonesians died due to peptic ulcer. The risk factors for peptic ulcers were $H$ pylori infection; chronic use non-steroid anti-inflammatory drugs; excessive alcohol consumption; and tobacco smoking. ${ }^{1-4}$
A. cordifolia or binahong is one of the Indonesian medicinal plants that are empirically used to treat ulcer. It contains flavonoids, alkaloids, terpenoids, oleanolic acid, saponins, proteins, and ascorbic acid. There is limited research on pharmacological activity of $A$. cordifolia as an anti-peptic ulcer. $^{5-8}$ 
Table 1. Anti-Peptic Ulcer Liquid Formula

\begin{tabular}{lccc}
\hline \multirow{2}{*}{$\begin{array}{c}\text { Additional } \\
\text { Materials }\end{array}$} & \multicolumn{3}{c}{ A. cordifolia extract 200 $\mathbf{~ m g} / \mathbf{k g}$ body weight } \\
\cline { 2 - 4 } & Formula 1 (\%) & Formula 2 (\%) & Formula 3 (\%) \\
\hline USP Syrup & 50 & 50 & 50 \\
Sodium CMC & 0.5 & - & - \\
Sorbitol & 20 & 20 & - \\
Sodium benzoate & 0.2 & 0.2 & 0.2 \\
Apple essence & $\mathrm{qs}$ & $\mathrm{qs}$ & $\mathrm{qs}$ \\
Distilled water ad & 100 & 100 & 100 \\
\hline
\end{tabular}

Sodium CMC is one of the most common suspending agent used in liquid formulation. It is hygroscopic, relatively stable in a liquid solution with a $\mathrm{pH}$ of $2.0-10$. Sorbitol is a preferable wetting agent due to its pleasant sweet taste and can act as stabilizer. ${ }^{9,10} \mathrm{We}$ conducted this study to evaluate the effect of different formulas on anti-peptic ulcer activity of $A$. cordifolia leaves extract in male Wistar rats.

\section{Methods}

\section{Materials}

The materials used in this study included A. cordifolia leaves which is obtained from Manoko, Lembang, Indonesia; distilled water, $95 \%$ and $80 \%$ ethanol, toluen, chloroform P, ammonia, Dragendorff reagent, Mayer reagent, hydrochloric acid, sodium hydroxide, magnesium powder, amyl alcohol, iron (III) chloride, gelatin, sodium stearate, Liebermann-Burchard, 10\% formalin, USP standard syrup, carrageenan,

Table 2. Ulcer Assessment

\begin{tabular}{lc}
\hline Ulcer & Score \\
\hline Normal gastric & 1 \\
Bleeding spots & 2 \\
The number of ulcers $1-3$ & 3 \\
The number of ulcers $4-6$ & 4 \\
The number of ulcers $7-9$ & 5 \\
The number of ulcers $>9$ & 6 \\
perforation & \\
\hline
\end{tabular}

sodium benzoate, and apple essence.

Tools

Tools used in this study included light microscope (Olympus BX51 $($ )), freeze dryer (Tecstar $(\mathbb{R})$, oral syringes, paper $\mathrm{pH}$ indicator, mixer, and silica plate GF 254.

\section{Animal model}

Animals used in this study were white male Wistar rats aged 2-3 months (150-250 g) Aclimatization was performed for one week before the experiment.

Extraction and formulation of the suspension A. cordifolia leaves were extracted using decoction method. The ratio between the leaves and water was 1:8. The leaves were boiled for 30 minutes. The extract was then filtered and dried using freeze dryer. The yield was calculated. Phytochemical screening was then conducted to determine secondary metabollites in the extract.

Table 3. Damage in Mucosal Integrity

\begin{tabular}{lc}
\hline Damage & Score \\
\hline No pathological change & 0 \\
Eithelial desquamation & 1 \\
Erosion of epithelium surface & 2 \\
Ulcer in epithelium & 3 \\
\hline
\end{tabular}


Table 4. Evaluation of Formula

\begin{tabular}{|c|c|c|c|c|c|c|c|}
\hline \multirow{2}{*}{$\begin{array}{c}\text { Evalua- } \\
\text { tion }\end{array}$} & \multirow{2}{*}{ Formula } & \multicolumn{3}{|c|}{ Organoleptic } & \multirow{2}{*}{$\mathbf{p H}$} & \multirow{2}{*}{ Viscosity } & \multirow{2}{*}{$\begin{array}{l}\text { Specific } \\
\text { gravity }\end{array}$} \\
\hline & & Color & Flavour & Aromatic & & & \\
\hline \multirow{3}{*}{ Week 1} & 1 & +++ & +++ & +++ & 7.6 & 52 & 1.093 \\
\hline & 2 & +++ & +++ & +++ & 7.82 & 14 & 1.079 \\
\hline & 3 & +++ & +++ & +++ & 7.53 & 8 & 1.046 \\
\hline \multirow{3}{*}{ Week 2} & 1 & +++ & +++ & +++ & 7.59 & 52 & 1.093 \\
\hline & 2 & +++ & +++ & +++ & 7.79 & 14 & 1.079 \\
\hline & 3 & +++ & +++ & +++ & 6.64 & 8 & 1.045 \\
\hline \multirow{3}{*}{ Week 3} & 1 & +++ & +++ & +++ & 7.59 & 52 & 1.093 \\
\hline & 2 & +++ & +++ & +++ & 7.79 & 14 & 1.079 \\
\hline & 3 & +++ & ++ & ++ & 6.44 & 8 & 1.044 \\
\hline \multirow{3}{*}{ Week 4} & 1 & +++ & +++ & +++ & 7.59 & 52 & 1.093 \\
\hline & 2 & +++ & +++ & +++ & 7.79 & 14 & 1.078 \\
\hline & 3 & +++ & ++ & + & 6.44 & 7 & 1.022 \\
\hline
\end{tabular}

Three formulas were used i.e., i) a combination of sodium carboxymethylcellulose (CMC) and sorbitol; ii) only sorbitol; iii) extract only. The complete formula of the liquid preparation can be seen in the table 1. Formulas were then evaluated to examine organoleptic properties, $\mathrm{pH}$, viscosity, and specific gravity.

\section{Anti-peptic ulcer activity}

The rats were divided into 6 groups, i.e., positive control (sucralfate $35 \mathrm{mg} / \mathrm{kg}$ body weight); negative control ( $80 \%$ ethanol); normal control; and 3 formulas. Animal was fasting for 18 hours before the administration of the treatment. One hours after the administration of the treatment, all groups except normal control were given $80 \%$ ethanol $15 \mathrm{ml} /$ $\mathrm{kg}$ bw to induce peptic ulcer. After 4 hours, animals were sacrificed. ${ }^{11}$ Anti-peptic ulcer activity was evaluated using direct observation on rats gastric mucosa, and histopathology assessment. Gastric $\mathrm{pH}$, the number and severity of ulcers, the ratio of ulcer inhibition were measured. Gastric histopathology assessment was performed using hematoxylin staining with eosin. Mucosal damage was measured. Statistical analysis was conducted using analysis of variance (ANOVA). $\mathrm{P}<0.05$ defined statistical significance.

Table 5. Number and Severity of Ulcers

\begin{tabular}{lcc}
\hline Group & Average number of ulcers & Average severity of ulcers \\
\hline Normal Control & $0 \pm 000$ & $0 \pm 000$ \\
Negative Control & $5.75 \pm 4.112$ & $4.5 \pm 2.380$ \\
Positive Control & $0.25 \pm 0.500$ & $0.25 \pm 0.500$ \\
Formula 1 & $0.5 \pm 0.577 \mathrm{~b}$ & $0.5 \pm 0.577 \mathrm{~b}$ \\
Formula 2 & $0.25 \pm 0.500 \mathrm{~b}$ & $0.25 \pm 0.500 \mathrm{~b}$ \\
Formula 3 & $3.5 \pm 2.380 \mathrm{a}, \mathrm{c}$ & $3.5 \pm 0.577 \mathrm{a}, \mathrm{c}$ \\
\hline
\end{tabular}

Description: $\mathrm{a}=$ different with normal group, $\mathrm{b}=$ different with the positive control, $\mathrm{c}=$ different with the negative control 
Table 6. Peptic Ulcer Index and Inhibition Percentage

\begin{tabular}{lcc}
\hline Group & Peptic Ulcer Index & Inhibition Percentage (\%) \\
\hline Normal Control & 0.00 & 100.00 \\
Negtive Control & 2.05 & 0.00 \\
Positive Control & 0.06 & 96.95 \\
Formula 1 & 0.15 & 92.68 \\
Formula 2 & 0.06 & 96.95 \\
Formula 3 & 1.40 & 31.71 \\
\hline
\end{tabular}

\section{Results and Discussion}

The extraction of $250 \mathrm{~g}$ of $A$. cordifolia leaves with 21 of distilled water resulted in $46 \mathrm{~g}$ of dried extracts (18.4\%). Phytochemical screening showed that the extract and all suspensions contained alkaloid, phenol, tannin, quinones, flavonoids, monoterpene sesquiterpene, steroid, and triterpenoide.
Evaluation of characteristics of formula for 1 month is presented in the table 4 . The addition of sodium carboxymethylcellulose and sorbitol affected the organoleptic properties, $\mathrm{pH}$, viscosity, and specific gravity. Formula 1 and 2 showed good characteristics.
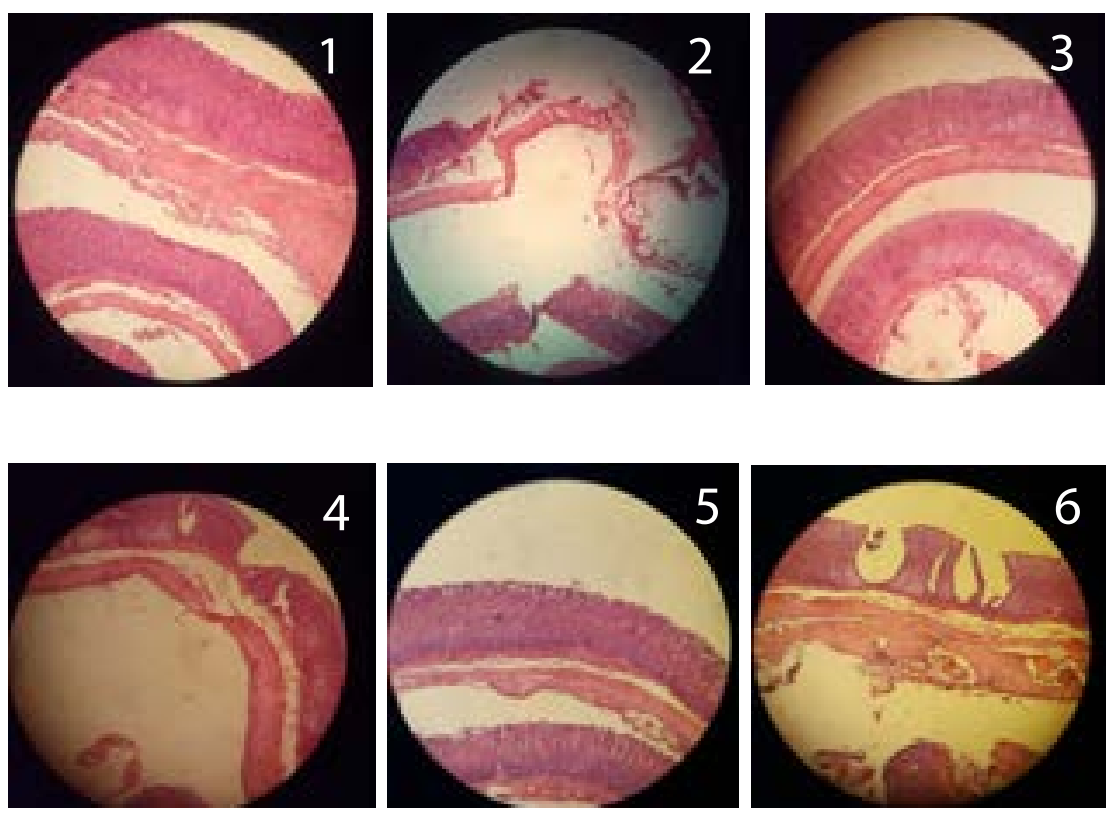

Figure 1. Histopathology of Male Wistar Rats Gastric

Description: $\quad \begin{aligned} & 1=\text { Normal control } \\ & 2=\text { Negative control } \\ & 3=\text { Positive control } \\ & 4=\text { Formula } 1 \\ & 5=\text { Formula } 2 \\ & 6=\text { Formula } 3\end{aligned}$


Anti-pepticulcer activity test was conducted to evalute which formula that showed strongest activity. The strongest ulcer inhibition was shown by formula 2 , with $96.95 \%$ inhibition. It was followed by formula 1 with $92.68 \%$ inhibition, while formula 3 only inhibited $31.70 \%$ of the ulcers.

Gastric histopathology observation also showed that formula 2 exhibited better results. In the formula 2 , the average gastric mucosal damage was 0.25 , indicating no pathological change of the mucosa. Based on Barthel-Spoiled indicator, epithelial desquamation and surface erosion were observed in the ulcer. Addition of sodium carboxymethylcellulose and sorbitol could influence the anti-ulcer activity since it might affect the absorption rate and bioavailability of the active compounds. ${ }^{11-13}$

\section{Conclusion}

A. cordifolia leaves extract with the addition of sorbitol showed the strongest anti-peptic ulcer activity.

\section{Acknowledgements}

None declared.

\section{Funding}

None.

\section{Conflict of Interest}

None declared.

\section{References}

1. Prabhu V, Shivani A. An overview of history, pathogenesis and treatment of perforated peptic ulcer disease with evaluation of prognostic scoring in adults. Annals of Medical Health Science Research. 2014;4(1):22-29.

2. Bashinskaya B, Nahed BV, Redjal N, et al. Trends in peptic ulcer disease and the identification of Helicobacter pylori as a causative organism. Journal of Global Infectious Disease. 2011;3(4):366-370.

3. Lee SP, Sung IK, Kim JH. Risk factors for the presence of symptoms in peptic ulcer disease. Clinical Endoscopy. 2016;50(6):578-584.

4. Suzuki RB, Cola RF, Cola LT, et al. Different risk factors influence peptic ulcer disease development in a Brazilian population. World Journal of Gastroenterology. 2012;18(38):5404 5411.

5. Yuniarti WM, Lukiswanto BS. Effects of herbal ointment containing the leaf extracts of Madeira vine (Anredera cordifolia (Ten.) Steenis) for burn wound healing process on albino rats. Veterinary World. 2017;10(7):808-813.

6. Astuti SM, Mimi SAM, Retno ABM. Determination of saponin compound from Anredera cordifolia (Ten) steenis plant (Binahong) to potential treatment for several diseases. Journal of Agricultural Science. 2011;3(4):224-232.

7. Garmana AN, Sukandar EY, Fidrianny I. Preliminary study of blood pressure lowering effect of Anredera cordifolia (Ten) steenis on Wistar rats. International Journal of Pharmacy Research. 2016;8(2):300-304.

8. Kumar SP, Prasan ND. Development and evaluation of poly herbal syrup from some herbs used as expectorant. World Jurnal of Pharmacy And Pharmaceutical Sciences. 2013;2(5):3850.

9. Ogaji IJ, Hoag SW. Effect of grewia gum as a suspending agent on ibuprofen pediatric formulation. AAPS Pharmaceutical Science and Technology. 2011;12(2):507513. Tiwari P, Kumar B, Kaur M, et al. Phytochemical screening and extraction. Internationale Pharmaceutica Sciencia. 2011;1(1):98-106.

10. Ulfah M. Preventive and curative activity evaluation of Binahong (Anredera 
cordifolia) water extracts in peptic ulcer [Thesis]. Bandung: Bandung Institute of Technology; 2016.

11. Hu L, Shi Y, Li JH, et al. Enhancement of oral bioavailability of curcumin by a novel solid dispersion system. AAPS Pharmaceutical Science and Technology 2015;16(6):1327-1334.

12. Moghimipour E, Salimi A, Rezaee S. Influence of flocculating agents and structural vehicles on the physical stability and rheological behavior of nitrofurantoin suspension. Journal of Natural Medicinal Products. 2014;9(2):e12716.

13. Savjani KT, Gajjar AK, Savjani JK. Drug solubility: importance and enhancement techniques. ISRN Pharmaceutics. 2012;2012:195727. 